\title{
A COMPARATIVE EVALUATION OF MICROLEAKAGE OF GLASS IONOMER RESTORATION WITH DIFFERENT SURFACE PROTECTORS - AN IN-VITRO STUDY
}

\author{
Nupur Ninawe ${ }^{1}$, Ullal Anand Nayak ${ }^{2}$, Priya Nagar ${ }^{3}$, Vishal Khandelwal ${ }^{4}$, Suyash Jain ${ }^{5}$, Ambika Shrivastava Gupta ${ }^{6}$ \\ ${ }^{1}$ Assistant Professor, Department of Pedodontics, \& Preventive Dentistry, Government Dental College, Nagpur. \\ ${ }^{2}$ Professor and HOD, Department of Pedodontics \& Preventive Dentistry, NIMS Dental College, Jaipur, Rajasthan \\ ${ }^{3}$ Associate Professor, Department of Pedodontics \& Preventive Dentistry, Krishnadevaraya College of Dental Sciences and Hospital, \\ Bangalore. \\ ${ }^{4}$ Reader, Department of Pedodontics, Index Dental College, Indore \\ ${ }^{5}$ Assistant Professor, Department of Pedodontics and Preventive Dentistry, Hitkarni Dental College, Jabalpur. \\ ${ }^{6}$ Reader, Department of Prosthodontics and Maxillofacial Prosthesis, Rishiraj College of Dental Sciences and Research Centre, Bhopal
}

Corresponding Author: Nupur Ninawe Mobile: +91- 9923765602 E-mail : nupurgovind@gmail.com

Received:29 $9^{\text {th }}$ April 2014 Accepted: $26^{\text {th }}$ July 2014 Online: $20^{\text {th }}$ Sept 2014

\begin{abstract}
Aim: All the restorative material whatsoever introduced till-date have an inherent disadvantage of microleakage measurable different grades. The present study comparatively evaluates the micro-leakage of glass ionomer restoration with different surface protection methods. Methodology: 36 premolars were obtained without any cracks or restorations for the study. Teeth were stored in distilled water containing thymol crystals till the beginning of the study. The teeth were randomly divided into 3 groups based on surface protectors used. Group I is GC Fuji Varnish, Group II is vaseline and Group III is G-Coat plus along with GIC restoration. Class V cavities were prepared of dimensions mesio-distal width of $3 \mathrm{~mm}$, occluso-gingival length of $2 \mathrm{~mm}$, and a depth of $1.5 \mathrm{~mm}$ on buccal and lingual surfaces with a high-speed hand-piece with airwater spray. Results: Kruskal- Wallis test was applied and Vaseline group showed significantly less microleakage compared to G-Coat plus i.e. G-Coat plus exhibited significantly higher microleakage compared to other groups. Conclusion: Evaluation of micro-leakage of glass ionomer cements using various surface protecting agents, Vaseline was considered the best surface protecting agent maintaining the water balance and showing no micro-leakage.
\end{abstract}

Key words: Glass Ionomer restoration, Micro-leakage, Surface protection.

\section{Introduction}

Most dental materials permit the microleakage of bacteria and bacterial products from oral fluids to reach dentin. Microleakage defined as the movement of bacteria, fluid, molecules or air between prepared cavity wall and applied restorative material. ${ }^{1}$ Thus, an understanding of the clinical consequences of micro-leakage demands that we analyze the permeability characteristics of dentin. The more dentin surface that is exposed during tooth preparation, the greater the potential for micro-leakage. Thicker dentin is less permeable than thin dentin. Dentin over pulp horns is more permeable than central dentin. Similarly, the dentin making up axial walls is more permeable than dentin forming the pulpal floor of cavities. Coronal dentin is much more permeable than root dentin. ${ }^{\prime}$ The presence of microleakage may lead to postoperative problems such as bacterial accumulation, fluid flow in the gap and detachment of restoration.

Conventional glass-ionomer cement, which is a popular restorative material commonly used in dentistry for a long time, is formed by an acid-base reaction between aluminosilicate glass and 40 $50 \%$ aqueous solution of acrylic acid/itaconic acid copolymer stabilized with a $5 \%$ tartaric acid. $^{2-4}$ Ionomer cements are sensitive to hydration and dehydration during their initial setting 
and are frequently protected by coating materials. The application of surface protection seems to preserve the water balance in the system. ${ }^{5}$ Another advantage of using such surface protectors is that they fill small surface voids and defects and may help to preserve the original color of the restorations by reducing the uptake of stains. ${ }^{6}$

\section{MATERIALS AND METHODS}

Specimen selection - 36 premolars were obtained without any cracks or restorations for the study.

Specimen Storage -The teeth were stored in distilled water containing thymol crystals till the beginning of the study. The teeth were randomly divided into 3 groups.

Dye application - The teeth were evaluated for marginal micro-leakage by immersing in $0.5 \%$ basic fuschin dye for 24 hours.

Table 1: Selection of Groups

\begin{tabular}{|c|c|}
\hline GROUPS & MATERIAL \\
\hline I & GC Fuji Varnish \\
\hline II & Vaseline \\
\hline III & CoaGPlus \\
\hline
\end{tabular}

\section{CAVITY PREPARATION}

Class V cavities were prepared of dimension given on all of the selected teeth (mesio-distal width of $3 \mathrm{~mm}$, occluso-gingival length of $2 \mathrm{~mm}$, and a depth of 1.5 $\mathrm{mm}$ ) on buccal and lingual surfaces with a high-speed hand-piece with air-water spray straight fissure bur. On all of the selected teeth on buccal and lingual surface, restoration with type II glass ionomer cement was mixed according to manufacturer's instructions and the cavities were restored. Surface protection was done for all the teeth as per the groups they were divided. Group I is GC Fuji Varnish, Group II is vaseline and Group III is G-Coat plus along with GIC restoration (Table 1).
After surface protection all teeth were kept undisturbed for 4 minutes till the initial set of GIC was complete. All the teeth were stored in distilled water for 24 hours. The teeth in each group were thermocycled for 500 cycles each between water baths of $5^{\circ} \mathrm{C}$ and $55^{\circ} \mathrm{C}$. Immersion time was approximately 30 seconds in each bath.

DYE: All the teeth were coated with nail varnish in all areas except the restoration and $1 \mathrm{~mm}$ surrounding it .The teeth were evaluated for marginal micro-leakage by immersing in $0.5 \%$ basic fuschin dye for 24 hours. The use of dye was equally effective in demonstrating micro-leakage and each penetrated the tooth or restoration interface. Following removal from the solution they were subsequently rinsed under running water to remove dye and dried at room temperature.

The specimens were sectioned longitudinally through the center of the restorations with a diamond saw such that the restoration were sectioned in its centre. The degree of dye penetration was then graded at $40 \mathrm{X}$ original magnification with a stereomicroscope using the following scale of 0-3 scoring system was used to evaluate the micro-leakage as shown in the fig.

$0=$ No dye penetration

$1=$ Dye penetration up to one-third of the cavity wall

$2=$ Dye penetration more than one-third, but less than two-thirds of the cavity wall

$3=$ Dye penetration more than two-thirds, or to the full extent of the cavity wall.

\section{RESULTS}

When Kruskal Wallis test was applied we found that Vaseline group showed significantly less microleakage than G-Coat plus on the buccal side (Table 2). On palatal side when group III i.e. G-Coat plus group exhibited more micro-leakage which was highly significant when compared to other 2 groups. 


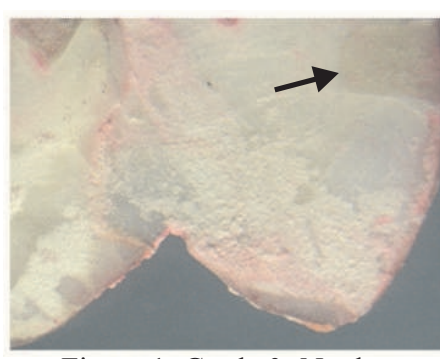

Figure 1: Grade 0- No dye

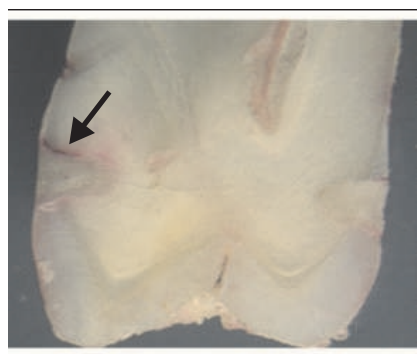

Figure 2: Grade I- Dye Penetration

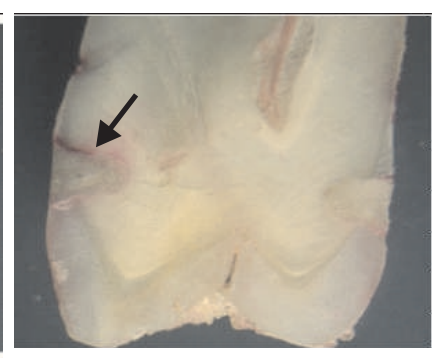

Figure 3: Grade II Dye Penetration more than half of cavity depth.

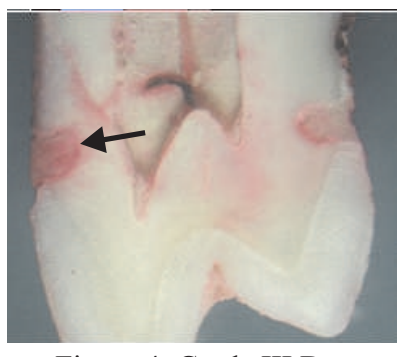

Figure 4: Grade III Dye penetration involve axial wall

Table 2: Kruskal-Wallis test' values

\begin{tabular}{|l|c|c|c|c|c|}
\hline Character & Mean & Mean & ' $t$ ' value & Probability & Significance \\
\hline BUCCAL & & & & & \\
\hline Group I \& Group II & 1.50 & 1.17 & 0.522 & 0.469 & NS \\
\hline Group I \& Group III & 1.50 & 2.17 & 2.265 & 0.132 & NS \\
\hline Group II \& Group III & 1.17 & 2.17 & 4.580 & 0.032 & Significant \\
\hline PALATAL & Mean & Mean & 't'value & Probability & Significance \\
\hline Group I \& Group II & 1.33 & 0.83 & 1.90 & 0.167 & NS \\
\hline Group I \& Group III & 1.33 & 2.33 & 7.36 & 0.006 & Highly significant \\
\hline Group II \& Group III & 0.83 & 2.33 & 8.99 & 0.002 & Highly significant \\
\hline
\end{tabular}

Table 3: Comparison of microleakage of Class V Restorations

\begin{tabular}{|l|c|c|c|c|c|}
\hline & & & & & \\
\hline Group I & 1.50 & 1.33 & 0.278 & 0.597 & NS \\
\hline & & & & & \\
\hline Group II & 1.17 & 0.83 & 0.447 & 0.504 & NS \\
\hline & & & & & \\
\hline Group III & 2.17 & 2.33 & 0.160 & 0.688 & NS \\
\hline
\end{tabular}

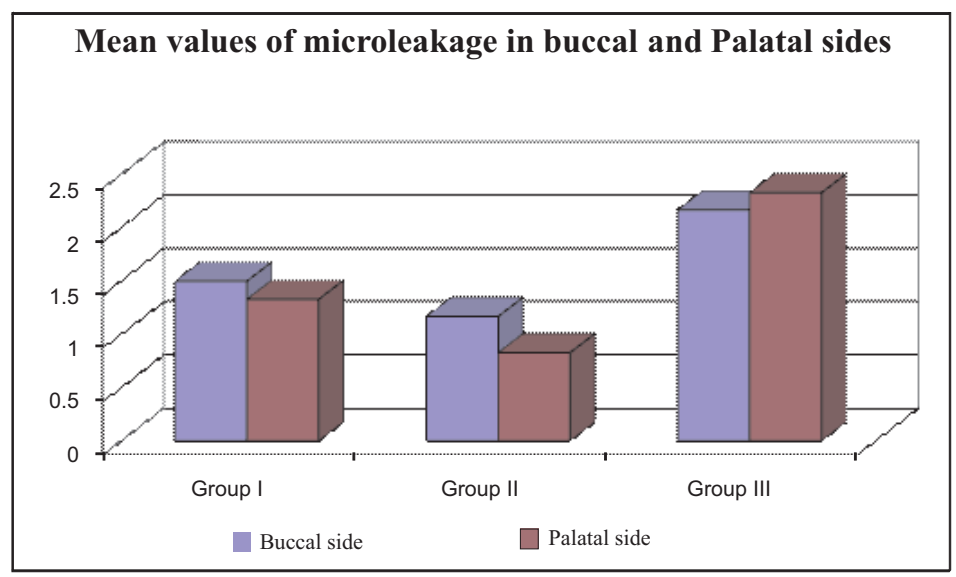

Graph 1: Mean values of microleakage in buccal and Palatal sides 
When Kruskal Wallis test was applied we found that Vaseline group showed significantly less microleakage than G-Coat plus on the buccal side. On palatal side when group III i.e. G-Coat plus group exhibited more micro-leakage which was highly significant when compared to other 2 groups. (Table 3, Graph 1)

\section{DISCUSSION}

Conventional Glass Ionomers (GIC) has been advocated as a restorative material because of their ability to chemically bond to tooth structure and release fluoride. They are widely used in dentistry for restoration, as a liner or base, and luting cements. ${ }^{7}$ Conventional GIC's are most moisture sensitive restorative materials. Glass-ionomers are sensitive to moisture in the early stages of placement. ${ }^{8}$ This may result in either washing out of reacting ions from the immature cement by saliva or, in patients who tend to breathe through the mouth, in desiccation and arrest of the setting reaction. Both, effects are undesirable, and to overcome the problems, dentists are advised to cover freshly placed cement with an impervious layer of varnish, petroleum jelly, or liquid resin bonding agent. ${ }^{8}$ Immediately after aluminosilicate glass powder is mixed into an aqueous solution of polymer of acrylic acid and the chemical acid-base reaction starts. According to Gemalmaz et al when GIC restorations were contaminated by moisture, their mechanical strength decreased and the surface of material eroded or wore rapidly. ${ }^{9}$ The ability of glass ionomer to minimize the extent of micro-leakage at the tooth or restoration interface is an important factor in preceding clinical success.

Studies have shown surface protection during the initial setting of glass ionomer cement. Various surface coating agents like Cocoa butter, waterproof varnish, and even nail varnish have been recommended. ${ }^{10-12}$ In the present study the best surface protecting agent was the Group II.The flaking of $\mathrm{G}$ coat plus more evident as compare to Fuji varnish and Vaseline. In one of the study by Hotta et $\mathrm{al}^{13}$ the varnish material after immersion in water which was not seen with Vaseline. Glass ionomers are sensitive to hydration and dehydration during the initial set and protected by coating materials (Asmussen 1983, Earl, Hume and Mount 1985).In the present study artificial saliva was not used and micro-leakage was checked using the surface protecting agents. The opening of stenson's duct is at the level of maxillary 1st and 2nd molar and therefore it directly does not correlate with our study. Thus it does not have any relevant significance.

\section{CONCLUSION}

Evaluating the micro-leakage of glass ionomer cements using various surface protecting agents Vaseline considered the best surface protecting agent maintaining the water balance and showing no microleakage. It is clear from the current study that petroleum jelly is only moderately effective at protecting the cement from water and that the cement matures to a state of increased surface hardness if cured in an environment completely protected from exposure to water.

\section{REFERENCES}

1. Pashley DH. Clinical considerations of microleakage. J Endod. 1990; 16(2):70-77.

2. Craig RG, Powers JM. Restorative dental materials.11th ed, Mosby Inc., St. Louis, 2002; 197-284.

3. Upadhya NP, Kishore G. Glass ionomer cement -the different generations. Trends Biomater Artif Organs 2005; 18: 158165.

4. Wilson AD. Developments in glass-ionomer cements. Int J Prosthodont 1989; 2: 438-446.

5. Sidhu SK, Watson TF. In vitro surface treatment and water balance of resin-modified glass- ionomers. J Dent Res 1995; 74: 475 .

6. Bouschlicher MR, Vargas MA. Effect of dessication on microleakage of glass-ionomer restorative materials. J Dent Res 1995; 74: 109 .

7. Wilson AD, McLean JW.Glass Ionomer .London: Quintessence Publishing; 1988:83-99.

8. Wasson EA, Nicholsiin JW. A study of the relationship between the setting chemistry and properties of modified glass polyalkenoate cements. Br Polym J 1990; 23; 179-183.

9. Gemalmaz D,Yoruc B,M Ozcan.Effect of early water contamination on solubility of glass ionomer luting cements.Journal of Prosthetic Dentistry 1998,80(4):474-478.

10. Asmussen E.Opacity of glass ionomer cements.Acta Odontol Scand; 1983; 41:155-57.

11. Earl MS,Hume WR ,Mount GJ. Effect of varnishes and other surface treatment on water movement across the glass ionomer cement surface. Aust Dent J 1985;30:298-301.

12. Rodrigues Garcia RC,De Goes MF.Influence of protecting agents on the solubility of glass ionomers.Am J Dent 1995;8:294-96.

13. Hotta m,Hirukawa H,Yamamoto K. Effect of coating materials on restorative glass ionomer cement surface. Oper Dent 1992; 17:57-61. 